\title{
Laboratory studies of collection efficiency of sub-micrometer aerosol particles by cloud droplets on a single-droplet basis
}

\author{
K. Ardon-Dryer, Y.-W. Huang, and D. J. Cziczo \\ Dept. of Earth, Atmospheric and Planetary Sciences, Massachusetts Institute of Technology, Massachusetts, USA \\ Correspondence to: K. Ardon-Dryer (karin.ardon@gmail.com)
}

Received: 5 January 2015 - Published in Atmos. Chem. Phys. Discuss.: 4 March 2015

Revised: 5 August 2015 - Accepted: 9 August 2015 - Published: 19 August 2015

\begin{abstract}
An experimental setup has been constructed to measure the collection efficiency (CE) of sub-micrometer aerosol particles by cloud droplets. Droplets of a dilute aqueous ammonium sulfate solution with an average radius of $21.6 \mu \mathrm{m}$ fall freely into a chamber and collide with sub-micrometer polystyrene latex (PSL) sphere particles of known sizes and concentrations. Two relative humidity (RH) conditions, $15 \pm 3 \%$ and $88 \pm 3 \%$, hereafter termed "low" and "high", respectively, were varied with different particles sizes and concentrations. After passing through the chamber, the droplets and aerosol particles were sent to the Particle Analysis by Laser Mass Spectrometry (PALMS) instrument to determine chemical compositions on a single-droplet basis. "Coagulated droplets" (droplets that collected aerosols) had mass spectra that contained signatures from both an aerosol particle and a droplet residual. CE values range from $2.0 \times 10^{-1}$ to 1.6 for the low-RH case and from $1.5 \times 10^{-2}$ to $9.0 \times 10^{-2}$ for the high-RH case. CE values were, within experimental uncertainty, independent of the aerosol concentrations. CE values in this study were found to be in agreement with previous experimental and theoretical studies. To our knowledge, this is the first collection experiment performed on a single-droplet basis with atmospherically relevant conditions such as droplet sizes, droplet charges and flow.
\end{abstract}

\section{Introduction}

The interplay between aerosol particles and water droplets in the atmosphere, especially in clouds, influences both aerosol and cloud properties. The major uncertainty in our understanding of climate arises from this interplay: the ability of an aerosol to affect cloud formation and, consequently, alter the global radiative balance (IPCC, 2007). When an aerosol particle comes in contact with a water droplet, the interaction can result in a collision followed by coalescence of the two. This process is known as "collection" or "coagulation". The collection process is considered an important mechanism that can "scavenge", and thereby remove, aerosol particles from the atmosphere (Starr and Mason, 1966; Owe Berg et al., 1970; Hampl and Kerker, 1972; Pranesha and Kamra, 1996). Collection can also affect cloud dynamics, the precipitation process and cloud lifetime, and thereby change the global radiation budget (Rasch et al., 2000; Croft et al., 2009).

In supercooled clouds, where droplets are present at temperatures below $0^{\circ} \mathrm{C}$, the collection process can have an effect on precipitation when the contacting aerosol initiates ice nucleation. The result is the creation of an ice crystal, a process known as "contact nucleation" (Vali, 1996). Contact can influence cloud lifetime and precipitation formation in mixed-phase clouds, which will also affect the global radiation budget. In order to understand the contact freezing process, it is important to determine the efficiencies at which the aerosol particles collide with a liquid droplet within a cloud.

Collection efficiency (CE) is the ability of a droplet to coagulate with the aerosol particles within the volume swept out as it falls. Several mechanisms and forces can affect the collection process. These include inertial impaction, Brownian diffusion, interception, electrical and other phoretic forces (see Fig. 1). Inertial impaction is defined as the impaction of particles that have sufficient inertia that they do not follow their original streamline around the droplet but instead travel close enough to the surface to result in a collision. Brownian diffusion refers to the movement of the particle due to collisions with air molecules. In this context it results in a "random walk" into the droplet surface. Interception is 


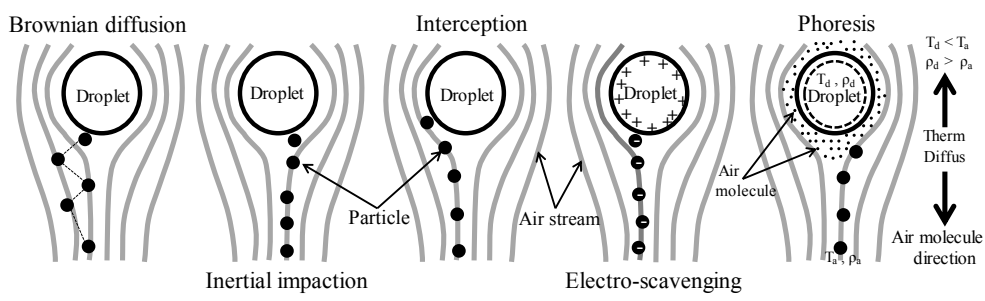

Figure 1. Mechanisms that affect the collection process of aerosol particles by water droplets. The mechanisms, from left to right, are Brownian diffusion, inertial impaction, interception, electro-scavenging and phoresis. $T_{\mathrm{d}}$ and $\rho_{\mathrm{d}}$ are the temperature and water molecule density at the droplet surface, while $T_{\mathrm{a}}$ and $\rho_{\mathrm{a}}$ are the ambient temperature and water molecule density. See text for additional description. Figure based on Ladino (2011).

the impaction of particles that follow a streamline that approaches the droplet within a distance equivalent to the particle radius. Electrical forces, also commonly termed electroscavenging or electrophoresis, occur when opposite electrical charges are present on the droplet and the particle, resulting in an attraction between the two. Other phoretic forces occur when a droplet evaporates or grows. These phoretic forces include thermophoresis and diffusiophoresis. Thermophoresis takes place when there is a temperature gradient between a droplet and its surroundings. When a droplet evaporates, its surface can become colder and aerosols will be drawn towards it. Diffusiophoresis, a counterforce to thermophoresis, occurs when there is a concentration gradient in water vapor, as is the case near an evaporating droplet. Higher water vapor concentration surrounding the droplet "pushes" particles outward. A review of the phoretic forces can be found in Pruppacher and Klett (1997).

The mechanisms described above are dependent on the size of the aerosol particle being collected. Whereas for large particles (radius $>1 \mu \mathrm{m}$ ) inertial effects dominate the collection process, small particle (radius $<0.1 \mu \mathrm{m}$ ) motion is dominated by Brownian diffusion and electro-scavenging (Wang and Pruppacher, 1977), where the effects of the latter are higher (Tinsley et al., 2001). Phoretic forces have a larger impact on particles in the intermediate size range (Wang and Pruppacher, 1977). This intermediate range, $0.1-1 \mu \mathrm{m}$, is normally termed the "Greenfield gap", and coincides with an observed minimum in CE (Greenfield, 1957). The particle radius of the Greenfield gap has also been observed to vary with the collecting droplet size (Tinsley et al., 2001).

Many factors, besides particle size, have been observed to affect CE (Byrne and Jennings, 1993). These include particle density (Chate and Kamra, 1997), turbulence (Grover and Pruppacher, 1985) and relative humidity (RH). Lower RH has been observed to correlate with higher CE values, apparently due to phoretic forces (Grover et al., 1977; Tinsley et al., 2001). Droplet size can impact CE, where lower values correlate with larger droplets (Lai et al., 1978; Pranesha and Kamra, 1996). Higher charge also correlates with higher CE, indicative of greater electrical force (Beard, 1974; Wang and Pruppacher, 1977; Lai et al., 1978; Barlow and Latham,
1983; Pranesha and Kamra, 1997a, b; Tinsley et al., 2000). It should be noted that the number of elementary charges used in previous work was often motivated by atmospheric observations: a few tens to hundreds of elementary charges for altostratus and stratocumulus clouds (Phillips and Kinzer, 1958; Beard et al., 2004) and hundreds to thousands of elementary charges in cumulonimbus clouds (Thomson and Iribarne, 1978; Marshall and Winn, 1982).

To date, there have been numerous experimental and theoretical studies of the collection process (Beard, 1974; Grover et al., 1977; Pranesha and Kamra, 1996; Park et al., 2005; Tinsley et al., 2006). Most of the experimental studies have focused on drizzle and raindrop sizes (Hampl and Kerker, 1972; Deshler, 1985; Pranesha and Kamra, 1997a, b), while few have used smaller cloud droplets (Ladino et al., 2011). A list of these studies is provided in Table 1. Note that only a few of the experiments reported aerosol concentrations and none mentioned whether different concentrations were compared.

Previous studies have relied on bulk collection of coagulated droplets followed by offline analysis to assess CE (Hampl et al., 1971; Deshler, 1985; Pranesha and Kamra, 1993; Chate and Kamra, 1997). Offline analytical instruments include mass spectrometry (Ladino et al., 2011), atomic absorption spectroscopy (Barlow and Latham, 1983; Pranesha and Kamra, 1996), fluorescence spectrometry (Byrne and Jennings, 1993) and neutron activation analysis (Beard, 1974). The efficiency determined from bulk collection of droplet results in a signal-to-noise issue where minimal collection events can fall below instrumental detection limits. The inability to determine multiple collection events by single droplets is another possible source of error. To our knowledge, no previous study allowed for determination of collection on a single-droplet basis with atmospherically relevant conditions of droplet size, droplet charge and flow, which are a key to many cloud processes, including contact nucleation. Another limitation of these bulk analytical methods lies in the aerosol type. Since each technique relies on certain property of the aerosol particles (such as fluorescence, radioactivity or atomic absorption), these experiments were restricted to a specific particle type exhibiting 
Table 1. Experimental results from previous studies of CE.

\begin{tabular}{|c|c|c|c|c|c|}
\hline Reference & Droplet radius $(\mu \mathrm{m})$ & Aerosol radius $(\mu \mathrm{m})$ & Aerosol type & Aerosol concentration $\left(\mathrm{cm}^{-3}\right)$ & RH \\
\hline Starr and Mason (1966) & $100-1000$ & $2.25,2.5,6.4$ & Spores, various & Not given & Not given \\
\hline Owe Berg et al. (1970) & $1210-1305$ & $7.5-15$ & PSL & Not given & Not given \\
\hline Hampl et al. (1971) & $710-2540$ & $0.2-0.5$ & $\mathrm{AgCl}$ & Not given & Not given \\
\hline Hampl and Kerker (1972) & 2540 & $53-2000$ & $\mathrm{AgCl}$ & Not given & Not given \\
\hline Beard (1974) & $200-425$ & $0.35-0.44$ & $\mathrm{In}\left(\mathrm{C}_{5} \mathrm{H}_{7} \mathrm{O}_{2}\right)_{3}$ & $5 \times 10^{4}$ & $97-99$ \\
\hline Kerker and Hampl (1974) & $940-2540$ & $0.15-0.6$ & $\mathrm{AgCl}$ & Not given & Not given \\
\hline Wang and Pruppacher (1977) & $150-2500$ & $0.25 \pm 0.03$ & $\mathrm{In}\left(\mathrm{C}_{5} \mathrm{H}_{7} \mathrm{O}_{2}\right)_{3}$ & $10^{17}-10^{18}$ & $23 \pm 2$ \\
\hline Lai et al. (1978) & $620,820,980$ & $0.15-0.45$ & $\mathrm{AgCl}$ & Not given & Not given \\
\hline Leong et al. (1982) & $56-93$ & $0.58-3.2$ & $\mathrm{MnO}_{4} \mathrm{P}_{2}$ & Not given & $\sim 30$ \\
\hline Barlow and Latham (1983) & $270-600$ & $0.2-1$ & Not given & $>1000$ & $50-70$ \\
\hline Deshler (1985) & $1200-1300$ & $0.03,0.06,0.13$ & Not given & $2 \times 10^{4}-1.4 \times 10^{5}$ & $60-97$ \\
\hline Byrne and Jennings (1993) & $400-550$ & $0.35-0.88$ & Not given & Not given & $50-80$ \\
\hline Pranesha and Kamra (1993) & $1800,2100,2400$ & $0.95,1.9,3.2$ & $\mathrm{NaCl}$ & Not given & Not given \\
\hline Pranesha and Kamra (1996) & $1800,2100,2400$ & $0.95,1.9,3.2$ & $\mathrm{NaCl}$ & Not given & $35-50$ \\
\hline Pranesha and Kamra (1997a) & $1800,2100,2400$ & $0.95,1.9,3.2$ & $\mathrm{NaCl}$ & Not given & $35-50$ \\
\hline Chate and Kamra (1997) & $1800,2100,2400$ & $1.5,2,3$ & $\mathrm{MgSO}_{4} \& \mathrm{MnCl}_{2}$ & Not given & $35-50$ \\
\hline Vohl et al. (2001) & $346,1680,2880$ & $0.16-0.24$ & $\mathrm{In}\left(\mathrm{C}_{5} \mathrm{H}_{7} \mathrm{O}_{2}\right)_{3}$ & Not given & 40 \\
\hline Ladino et al. (2011), Ladino (2011) & $12.8,15,18.2,20$ & $0.05-0.33$ & $\mathrm{LiBO}_{2}$ & $2 \times 10^{3}$ & $88 \pm 2$ \\
\hline Prodi et al. (2014) & $240-1075$ & $0.2-1$ & $\mathrm{NaCl}$ & Not given & $<100$ \\
\hline
\end{tabular}

that property. These constraints often limit the atmospheric applicability of the results.

Theoretical calculations of $\mathrm{CE}$ in a cloud environment have been the subject of many studies, driven by the necessity to explain aspects of both warm and cold precipitations. An experimental validation of the theoretical knowledge related to CE, particularly for droplet-aerosol collisions, is difficult and far from complete (Ladino, 2011). According to Santachiara et al. (2012), significant discrepancies between theoretical and experimental studies have been found for submicrometer particles in the "Greenfield gap", and the measured values can be 1 to 2 orders of magnitude higher than predicted. According to Wang et al. (2010), this disagreement could be because some physical processes considered in theoretical models are neglected, difficult to represent or hard to control in experimental studies.

The goal of this study was to determine the CE of submicrometer aerosol particles by cloud droplets. This study was conducted on a single-droplet basis with sensitivity to one or more collection events.

\section{Experimental methods}

\subsection{Experimental setup}

The CE experiments were performed in the new Massachusetts Institute of Technology Collection Efficiency Chamber (MIT-CEC). A schematic of the system is shown in Fig. 2. Aerosol particles and droplets were generated and separately passed into the MIT-CEC chamber, where they could fall, in a $0.48 \mathrm{~L} \mathrm{~m}^{-1}$ flow, and interact in the laminar flow environment of the chamber. Condensed-phase water was removed in dryers after the chamber, and the flow con-

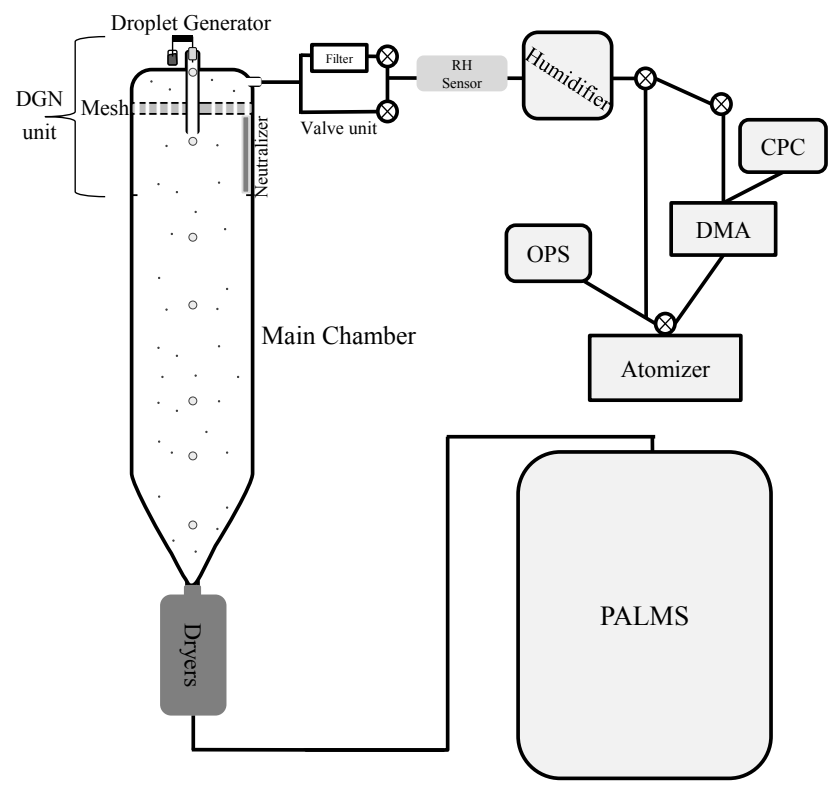

Figure 2. Experimental setup. DGN denotes the droplet generation and neutralizer unit. Additional description is provided in the text.

taining aerosol particles and droplet residuals was directed to the Particle Analysis by Laser Mass Spectrometry (PALMS) instrument for single-particle analysis.

Polystyrene latex (PSL) spheres with radius $0.025,0.125$, 0.25 and $0.475 \mu \mathrm{m}$ were used in the experiments. PSL spheres were wet generated using a Brechtel Manufacturing Inc. (BMI, Hayward, CA) model 9203 aerosol generation system. Condensed-phase water was removed by in-line dryers. Large particle (diameter $<0.35 \mu \mathrm{m}$ ) and residual concentrations were measured by an optical particle sizer (OPS; TSI 
Inc., Shoreview, MN, model 3330). Particles below diameter of $0.35 \mu \mathrm{m}$ were measured using a scanning mobility particle sizer (SMPS) consisting of a differential mobility analyzer (DMA; BMI Inc., model 2002) and a condensation particle counter (CPC; BMI Inc., MCPC model 1710). Similar concentrations were observed in the overlapping sensitivity region of both instruments. Two aerosol concentrations were used in the experiments: 50 and $100 \mathrm{~cm}^{-3}$. Particle losses were calculated by measuring the particle concentration at the entrance and at the bottom of the chamber (i.e., before PALMS). Particle losses were $14 \pm 10 \%$.

After the particles were generated, but before they entered the chamber, the particle flow either passed directly over an RH sensor (Omega EE08) in a low-RH experiment or through a humidifier and then over the RH sensor in a high-RH experiment. The humidifier, a glass container with a volume of $9 \mathrm{~L}$ containing Milli-Q $18.2 \mathrm{M} \Omega \mathrm{cm}$ water, was used to increase the RH of the airflow to $88 \pm 3 \%$. Two additional RH sensors were placed at the chamber top and bottom to monitor the temperatures and RH profiles. Valves were placed in line to either block or admit particles depending on the experimental phase described in the following paragraphs.

The overall length of the MIT-CEC is $160 \mathrm{~cm}$. The chamber was constructed of glass with stainless steel and aluminum ports for connections to the dryers, aerosol and droplet inputs. The upper part of the chamber, termed the droplet generator and neutralizer (DGN) unit, is a $21 \mathrm{~cm}$ long, $5 \mathrm{~cm}$ diameter stainless steel cylinder. This section contains a commercial droplet generator, a charge neutralizer, and ports for aerosol injection. A mesh grid is used to straighten the particle flow. Droplets are injected vertically downward through a tube to avoid contact with the aerosol particles until the lower portion of the DGN. A neutralizer, containing two polonium- 210 strips $(0.64 \mathrm{~cm}$ thickness and $15 \mathrm{~cm}$ long), is placed in the lower part of the DGN. The lower part of the DGN is connected directly to the main chamber, a single-jacketed glass column with an inner diameter of $5 \mathrm{~cm}$. The length of the jacketed area is $140 \mathrm{~cm}$. An aluminum cone reducer, $4 \mathrm{~cm}$ in length, is attached to the bottom of the main chamber in order to focus the flow into a variable length dryer used for condensed-phase water removal prior to analysis with PALMS.

A Microdrop Technologies dispenser system (Microdrop Technologies, Norderstedt, Germany, model MD-K-130) was used to generate droplets. This droplet generator (DG), based on piezo-driven inkjet printing technology, generates droplets with an average radius of $21.6 \pm 0.8 \mu \mathrm{m}$. A Microdrop CCD camera (model MD-O-538-85) and imaging system, with a total magnification of $120 \times$, was used to determine droplet size on a daily basis before the generator was set atop the chamber. The size differed slightly for the low- and high-RH experiments, 21.9 and $21.4 \mu \mathrm{m}$, respectively. Due to the position of the camera, droplet size could not be monitored during an experiment or within the cham- ber. Droplet size was, however, measured before and after the experiment, and the size was constant within the quoted uncertainty. Droplet size during experiments was also verified by the residual size after the droplets evaporated. Droplets were generated at $30 \mathrm{~Hz}$. This is a frequency much lower than previously used in other experimental works using cloud droplets (e.g., $1000 \mathrm{~Hz}$ in Ladino et al., 2011) where analysis was performed on a bulk basis. This rate yielded both a collection signal with PALMS and minimized possible dropletdroplet collisions inside the chamber.

As mentioned in the previous section, droplet and aerosol charge affect electro-scavenging forces and can therefore impact the collection rate. To determine the droplet charge, we utilized an electrometer (Liu and Pui, 1974) which was connected to the DG. Using the electrometer, we determined that $\sim 10^{4}$ elementary charges are imparted to each droplet upon production from the generator. The neutralizer reduces this charge to $400 \pm 400$ elementary charges. Aerosol charge distribution was assumed to be a Boltzmann distribution after neutralization where the most common charge state other than neutral is a single charge (Wiedensohler, 1988; Hinds, 1999).

The droplets were produced from a dilute ammonium sulfate $\left(\left(\mathrm{NH}_{4}\right)_{2} \mathrm{SO}_{4}\right.$; hereafter AS) solution, $0.08 \mathrm{~g} \mathrm{~L}^{-1}$. Dilute AS was used due to its atmospheric relevance as a condensation nucleus and in order to provide a chemically distinct signature for detection of droplet residuals with PALMS. Based on the original droplet size and solution concentration, and as verified by PALMS sizing, a single effloresced residual was $0.75 \mu \mathrm{m}$ radius.

The PALMS instrument determines size and chemical composition of a single-particle basis. A detailed description of the PALMS instrument has been published previously (Murphy and Thomson, 1995; Cziczo et al., 2006). In brief, particles enter an aerodynamic inlet, which focuses the particle stream. The particles then pass through two $532 \mathrm{~nm}$ $\mathrm{Nd}$ :YAG laser beams, yielding scattering signals that are used to trigger an excimer laser beam $(193 \mathrm{~nm})$. The time difference between the two scattering signals provides an aerodynamic size of the particle (Cziczo et al., 2006). The excimer laser ablates and ionizes the particle. The ions from each detected particle are ejected into a reflectron mass spectrometer and detected on a micro-channel plate (MCP), thus providing a mass spectrum of the particle.

\subsection{Data analysis}

Droplet residuals, PSL particles and coagulated droplets had distinct sizes and mass spectrum (Fig. 3). In positive ion mode, PSL particles had distinct signatures of their carbon chains at mass-to-charge ratio $(\mathrm{m} / \mathrm{z}) 12\left(\mathrm{C}_{1}\right), 24\left(\mathrm{C}_{2}\right), 36$ $\left(\mathrm{C}_{3}\right)$ and $48\left(\mathrm{C}_{4}\right)$; in many cases the carbons were associated with hydrogen. Droplet residuals had a signature at $m / z 18$ $\left(\mathrm{NH}_{4}\right)$ and $30(\mathrm{NO})$. It should be noted that the PSL spheres did not contain the droplet signature, nor did the droplets 

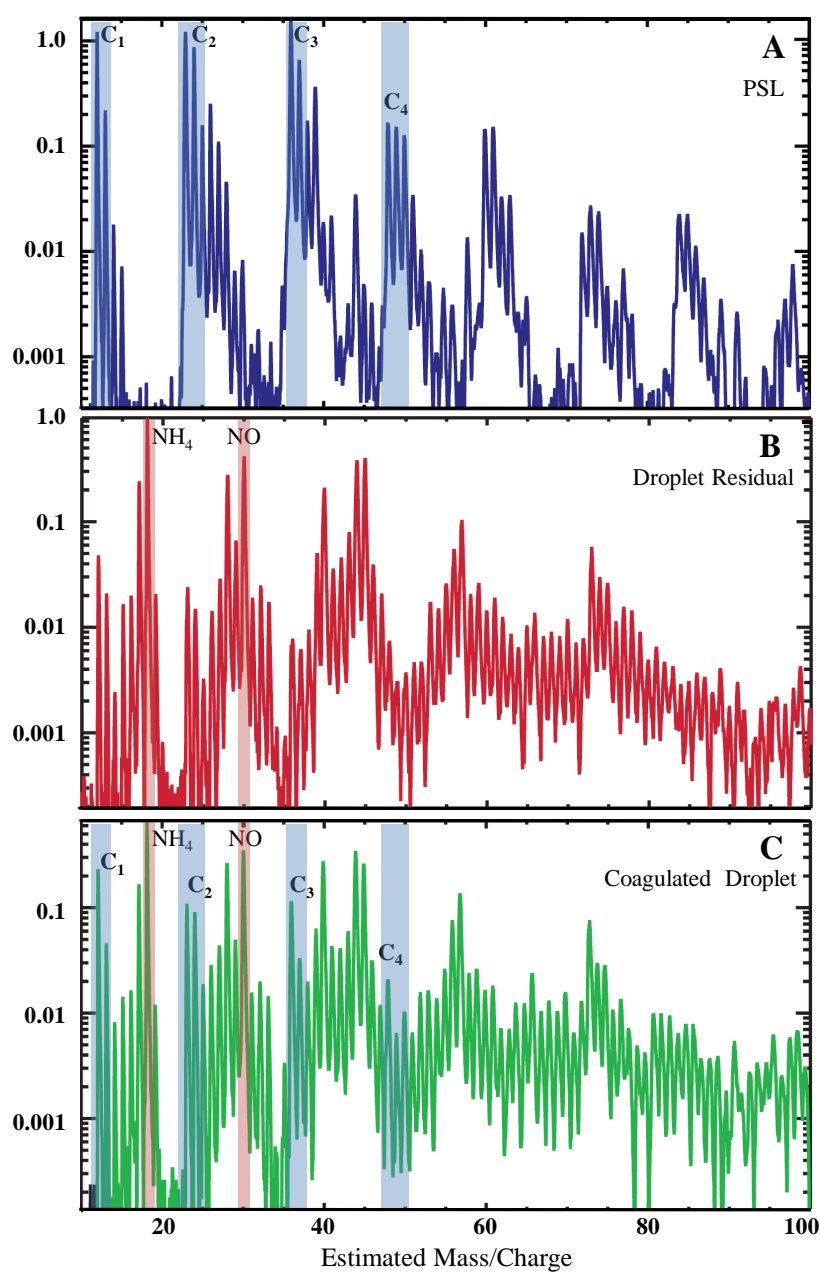

Figure 3. Mass spectra of a PSL particle (a), an evaporated droplet composed of dilute AS, termed a droplet residual (b), and a coagulated and evaporated droplet that contained both a PSL particle and residual AS (c).

contain a PSL signature. Coagulated droplets, on the other hand, exhibited mass spectra with signatures from both the droplet residuals and the PSL particles (Fig. 3c). In order to determine the presence or absence of a collection event, a coagulation index $(\mathrm{CI})$ was developed:

$$
\mathrm{CI}=\frac{\text { carbon signal }}{\text { ammonium sulfate signal }} .
$$

Each experiment started by passing only droplets through the chamber. This allowed for a reference case of maximum CI without collection based on $>1000$ droplets analyzed. After the reference spectra were obtained, aerosol particles were added to the chamber by opening the in-line valves. Each collection experiment contained at least 1000 analyzed droplets with a $\mathrm{CI}$ value greater than the baseline obtained from the droplet-only phase. CI for each droplet during a typical experiment is plotted in Fig. 4. The leftmost data comprise the baseline CI, in this case for $>2500$ droplets. The collection experiment is on the right where five collection events were observed. Using these data, an experimental collection ratio (ECR) was calculated:

$\mathrm{ECR}=\frac{\text { number of droplets that coagulated }}{\text { total number of droplets }}$.

For this experiment, 5 out of the 1189 droplets experienced collection, yielding an ECR of $4.2 \times 10^{-3}$. It should be noted that an experiment of PSL with AS residual (from the evaporated droplet) was performed. Several thousand spectra were examined with PALMS but no collection event was observed.

A CE value, normalized by the number of particles contained within the volume swept out by a falling droplet, was also calculated. This calculation takes into account a droplet's cross section, the aerosol concentration, and the effective interaction length of the chamber so that comparisons can be drawn between these data and previous experiments:

$\mathrm{CE}=\frac{\mathrm{ECR}}{\pi\left(R_{\mathrm{d}}+R_{\mathrm{a}}\right)^{2} L A_{\mathrm{c}}}$,

where $R_{\mathrm{d}}$ is the droplet radius; $R_{\mathrm{a}}$ is the aerosol radius; $A_{\mathrm{c}}$ is the aerosol number concentration and $L$ is the effective interaction length of the chamber; which defined as

$L=\frac{V_{\mathrm{d}} \cdot l}{V_{\mathrm{d}}+V_{\mathrm{a}}}$,

where $V_{\mathrm{d}}$ and $V_{\mathrm{a}}$ are the droplet terminal (settling) velocity and the velocity of the air carrying the particles, respectively, and $l$ is the length of the chamber before the droplets evaporate.

\subsection{Theoretical CE models}

Previous studies have theoretically determined the CE between droplets and aerosol particles (Slinn and Shen, 1970; Beard, 1974; Grover et al., 1977; Davenport and Peters, 1978; Wang et al., 1978; Park et al., 2005; Tinsley et al., 2000, 2006; Chate, 2005; Andronache et al., 2006; Feng, 2007; Croft et al., 2009; Tinsley, 2010; Wang et al., 2010; Tinsley and Leddon, 2013). In order to understand our experimental data, we compare them to a theoretical treatment of CE. This treatment includes Brownian diffusion, interception, inertial impaction, thermophoresis, diffusiophoresis and electro-scavenging. The total CE is the sum of these processes. The CE due to Brownian diffusion, interception and inertial impaction are based on Park et al. (2005), which expands on Jung and Lee (1998). Thermophoresis, diffusiophoresis and electro-scavenging are based on Wang et al. (2010), which expands on Andronache et al. (2006) and 
Davenport and Peters (1978). The efficiencies used here are

$$
\begin{aligned}
& E_{\text {Bdiff }}=2\left(\frac{\pi \sqrt{3}}{4 P e}\right)^{2 / 3} \\
& {\left[\frac{(1-\propto)\left(3 \frac{\mu_{\mathrm{w}}}{\mu_{\mathrm{a}}}+4\right)}{\left(1-\frac{6}{5} \propto^{1 / 3}+\frac{1}{5} \propto^{2}\right)+\frac{\mu_{\mathrm{w}}}{\mu_{\mathrm{a}}}\left(1-\frac{9}{5} \propto^{1 / 3}+\frac{1}{5} \propto^{2}+\propto\right)}\right]^{1 / 3},}
\end{aligned}
$$

$E_{\text {int }}=$

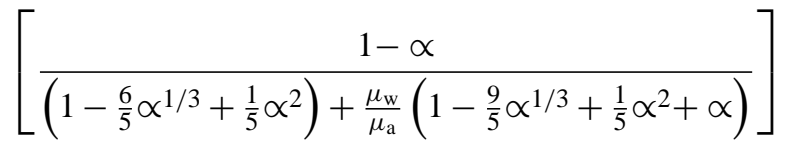
$\left[\frac{\left(D_{\mathrm{a}} / D_{\mathrm{d}}\right)}{1+\left(D_{\mathrm{a}} / D_{\mathrm{d}}\right)}+\frac{1}{2}\left(\frac{\left(D_{\mathrm{a}} / D_{\mathrm{d}}\right)}{1+\left(D_{\mathrm{a}} / D_{\mathrm{d}}\right)}\right)^{2}\left(3 \frac{\mu_{\mathrm{w}}}{\mu_{\mathrm{a}}}+4\right)\right]$,

$E_{\text {imp }}=\left(\frac{S t k}{S t k+0.35}\right)^{2}$,

$$
\begin{aligned}
& E_{\text {th }}= \\
& \frac{4\left[\frac{2 C_{\mathrm{c}}\left(K_{\mathrm{a}}+5 \frac{\lambda}{D_{\mathrm{d}}} K_{\mathrm{p}}\right) K_{\mathrm{a}}}{5 P\left(1+6 \frac{\lambda}{D_{\mathrm{d}}}\right)\left(2 K_{\mathrm{a}}+K_{\mathrm{p}}+10 \frac{\lambda}{D_{\mathrm{d}}} K_{\mathrm{p}}\right)}\right]\left(2+0.6 \operatorname{Re}^{1 / 2} \operatorname{Pr}^{1 / 3}\right)\left(T_{\mathrm{a}}-T_{\mathrm{d}}\right)}{D_{\mathrm{d}} V_{\mathrm{d}}},
\end{aligned}
$$

$$
E_{\mathrm{df}}=\frac{4\left[\frac{T_{\mathrm{a}} D_{\mathrm{w}}}{P}\left(\frac{M_{\mathrm{w}}}{M_{\mathrm{a}}}\right)^{1 / 2}\right]\left(2+0.6 \operatorname{Re}^{1 / 2} \operatorname{Pr}^{1 / 3}\right)\left(\frac{\rho_{\mathrm{a}}-\rho_{\mathrm{d}}}{T_{\mathrm{a}}-T_{\mathrm{d}}}\right)}{D_{\mathrm{d}} V_{\mathrm{d}}}
$$

$E_{\mathrm{ec}}=\frac{16 C_{\mathrm{c}} k_{\mathrm{ec}} Q_{r} q_{r}}{3 \pi \mu_{\mathrm{a}} D_{\mathrm{p}}^{2} D_{\mathrm{a}} V_{\mathrm{d}}}$,

where $E_{\text {Bdiff }}, E_{\mathrm{int}}, E_{\mathrm{imp}}, E_{\mathrm{th}}, E_{\mathrm{df}}$ and $E_{\mathrm{es}}$ are Brownian diffusion, interception, inertial impaction, thermophoresis, diffusiophoresis and electro-scavenging efficiencies, respectively. A full definition of all variables is provided in Table 2. These theoretical models include the known forces that affect $\mathrm{CE}$ values and which were measured or constrained by data in the experimental measurements presented here. It should be noted that, although these theoretical models were developed for large droplets, they have been used to calculate CE for sizes relevant to this work (Ladino, 2011).

\section{Result and discussion}

A total of 16 collection experiments were performed. The collection experiments were for four different aerosol sizes (with radius $0.025,0.125,0.25$ and $0.475 \mu \mathrm{m}$ ), each at two different concentrations (50 and $100 \mathrm{~cm}^{-3}$ ) and two different RH conditions ( $15 \pm 3$ and $88 \pm 3 \%)$. A full description

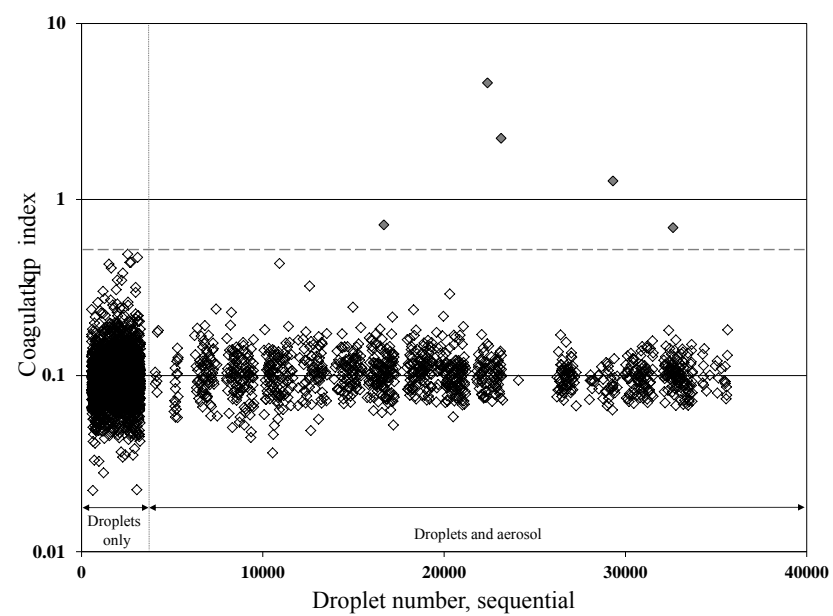

Figure 4. Coagulation index (CI), the ratio of PSL (aerosol) to AS (droplet residual) signal in a mass spectrum, for a typical experiment. In this experiment the $\mathrm{RH}$ was $15 \%$, droplet radius was $20 \mu \mathrm{m}$, and PSL particles were $0.125 \mu \mathrm{m}$ radius with a concentration of $100 \mathrm{~cm}^{-3}$. The $x$ axis represents the sequential analysis of single droplet residuals over the course of the experiment. Particles which exceed the ratio found when only droplets are analyzed (dashed line; the "droplets only" data acquired at the start of each experiment) are considered collection events. There are five collection events during this experimental period.

of the experiments is summarized in Table 3. All experiments were conducted at room temperature $\left(22.5 \pm 1.3^{\circ} \mathrm{C}\right)$. Droplet radius was $21.6 \pm 0.8 \mu \mathrm{m}$. Terminal (settling) velocity was calculated based on the experimental temperature and droplet size. The terminal velocity varied from 4.7 to $5.8 \mathrm{~cm} \mathrm{~s}^{-1}$. Total droplet evaporation time (i.e., residence in the generator section and experimental chamber) was calculated based on the average droplet size and the RH condition: 2.1 and $16.6 \mathrm{~s}$ for the low- and high-RH cases, respectively. The droplets' residence time in the chamber was 0.7 and $6.1 \mathrm{~s}$, for the lowand high-RH cases, respectively. Calculations of Reynolds numbers were performed using the experimental conditions and chamber geometry. Reynolds numbers from 0.12 to 0.16 were calculated and, based on this, we assume the aerosol particles and droplets interact in flow conditions close to laminar throughout the chamber.

Each collection experiment incorporated between 1039 and 4598 droplets. The droplets that coagulated were identified based on their $\mathrm{CI}$ as described in Sect. 2.2. ECRs were based on the ratio between the number of coagulated droplets to the total number of droplets per experiment and these values varied from $6.5 \times 10^{-4}$ to $8.6 \times 10^{-3}$ for the low-RH experiments and from $9.6 \times 10^{-4}$ to $4.9 \times 10^{-3}$ for the highRH experiments. The ECR was higher for the higher aerosol concentration experiments for most particles sizes; this is consistent with higher aerosol concentration increasing the chances for particles to coagulate with droplets. 
Table 2. Definition of acronyms and relevant units.

\begin{tabular}{|c|c|c|}
\hline Parameter & Definitions & Units \\
\hline$C_{\mathrm{c}}$ & Cunningham slip correction factor & {$[-]$} \\
\hline $\mathrm{CE}$ & Collection efficiency & {$[-]$} \\
\hline$D_{\mathrm{a}}$ & Aerosol particle diameter & {$[\mathrm{m}]$} \\
\hline$D_{\mathrm{d}}$ & Droplet diameter & {$[\mathrm{m}]$} \\
\hline$D_{\mathrm{W}}$ & Diffusivity of water vapor & {$\left[\mathrm{m}^{2} \mathrm{~s}^{-1}\right]$} \\
\hline$E_{\text {Bdiff }}$ & Brownian diffusion efficiency & {$[-]$} \\
\hline ECR & Experimental collection ratio & {$[-]$} \\
\hline$E_{\mathrm{ec}}$ & Electric charge efficiency & {$[-]$} \\
\hline$E_{\mathrm{df}}$ & Diffusiophoresis efficiency & {$[-]$} \\
\hline$E_{\text {imp }}$ & Inertial impaction efficiency & {$[-]$} \\
\hline$E_{\text {int }}$ & Interception efficiency & {$[-]$} \\
\hline$E_{\text {th }}$ & Thermophoresis efficiency & {$[-]$} \\
\hline$K_{\mathrm{a}}$ & Thermal conductivity of moist air & {$\left[\mathrm{kg} \mathrm{ms} \mathrm{s}^{-3} \mathrm{~K}^{-1}\right]$} \\
\hline$K_{\mathrm{p}}$ & Thermal conductivity of particles & {$\left[\mathrm{kg} \mathrm{ms} \mathrm{s}^{-3} \mathrm{~K}^{-1}\right]$} \\
\hline$M_{\mathrm{a}}$ & Molecular weight of air & {$\left[\mathrm{kg} \mathrm{mol}^{-1}\right]$} \\
\hline$k_{\mathrm{ec}}$ & $K$ constant for $E_{\mathrm{ec}}$ calculations equal to $9 \times 10^{9}$ & {$\left[\mathrm{~nm}^{2} \mathrm{C}^{-2}\right]$} \\
\hline Mw & Molecular weight of water & {$\left[\mathrm{kg} \mathrm{mol}^{-1}\right]$} \\
\hline$P$ & Atmospheric pressure & {$[\mathrm{Pa}]$} \\
\hline$P e$ & Peclet number & {$[-]$} \\
\hline $\operatorname{Pr}$ & Prandtl number of air & {$[-]$} \\
\hline$q_{r}$ & Mean charge on aerosol particles & {$[$ Coulomb, C] } \\
\hline$Q_{r}$ & Mean charge on droplets & {$[$ Coulomb, C] } \\
\hline$R_{\mathrm{a}}$ & Aerosol radius & {$[\mathrm{m}]$} \\
\hline$R_{\mathrm{d}}$ & Droplet radius & {$[\mathrm{m}]$} \\
\hline$R e$ & Reynolds number & {$[-]$} \\
\hline Stk & Stokes number & {$[-]$} \\
\hline$T_{a}$ & Temperature of air & {$[\mathrm{K}]$} \\
\hline$T_{\mathrm{d}}$ & Temperature at droplet surface & {$[\mathrm{K}]$} \\
\hline$V_{\mathrm{d}}$ & Droplet terminal velocity & {$\left[\mathrm{ms}^{-1}\right]$} \\
\hline$\mu_{\mathrm{W}}$ & Water viscosity & {$\left[\mathrm{kg} \mathrm{m}^{-1} \mathrm{~s}^{-1}\right]$} \\
\hline$\mu_{\mathrm{a}}$ & Air viscosity & {$\left[\mathrm{kg} \mathrm{m}^{-1} \mathrm{~s}^{-1}\right]$} \\
\hline$\rho_{\mathrm{a}}$ & Water vapor of water at air temperature & {$[\mathrm{Pa}]$} \\
\hline$\rho_{\mathrm{d}}$ & Water vapor of water temperature at droplet surface & {$[\mathrm{Pa}]$} \\
\hline$\lambda$ & Mean free-path length of air molecules & {$[\mathrm{m}]$} \\
\hline$\propto$ & Packing density of drops & {$\left[\mathrm{m}^{3}\right]$} \\
\hline
\end{tabular}

CE value was calculated for each experiment, based on the average droplet size measured from each experiment and when similar RH, aerosol size and concentration conditions were used. $\mathrm{CE}$ values, normalized to aerosol concentration and time, ranged from $2.0 \times 10^{-1}$ to 1.6 for the low- $\mathrm{RH}$ experiments and from $1.5 \times 10^{-2}$ to $9.0 \times 10^{-2}$ for the highRH experiments (see Fig. 5). These values are in a similar range to that found by previous works (Wang and Pruppacher, 1977; Lai et al., 1978). As shown in Fig. 5, no significant difference in CE values between the two aerosol concentrations (50 and $100 \mathrm{~cm}^{-3}$ ) was observed. Most previous experiments did not specify what aerosol concentration were used during their collection experiments (Hampl et al., 1971; Lai et al., 1978; Prodi et al., 2014). Those that did specify had a higher aerosol concentration, in most cases above atmospheric relevance except within polluted boundary lay- ers (above $1000 \mathrm{~cm}^{-3}$; Beard, 1974; Wang and Pruppacher, 1977; Barlow and Latham, 1983; Deshler, 1985; Ladino et al., 2011). The use of these high aerosol concentrations was likely due to the limitation of bulk analysis methods, as discussed in the Introduction, which required a high concentration for adequate signal.

It has been shown theoretically by Wang et al. (1978), Grover and Pruppacher (1985) and Ladino et al. (2011), and experimentally by Grover et al. (1977), that CE increases with decreasing RH. This is because a lower RH leads to an increase in the evaporation rate of the droplet, which strengthens the phoretic forces. Two RH conditions were measured in this experimental work: low $(15 \pm 3 \%)$ and high $(88 \pm 3 \%)$. Consistent with these previous works, we find a higher $\mathrm{CE}$ values for the low-RH experiments, by as much as 
Table 3. Particle size and concentration, RH, droplet size and total analyzed and experimental collection ratio (ECR; see text for details) for this study.

\begin{tabular}{lllllll}
\hline Experiment & $\begin{array}{l}\text { Particle } \\
\text { radius } \\
(\mu \mathrm{m})\end{array}$ & $\begin{array}{l}\text { Particle } \\
\text { concentration } \\
\left(\mathrm{cm}^{-3}\right)\end{array}$ & $\begin{array}{l}\text { RH } \\
(\%)\end{array}$ & $\begin{array}{l}\text { Droplet } \\
\text { radius } \\
(\mu \mathrm{m})\end{array}$ & $\begin{array}{l}\text { Total } \\
\text { number of } \\
\text { droplets }\end{array}$ & ECR \\
\hline 1 & $0.025 \pm 0.005$ & $48 \pm 3$ & 11 & $20.0 \pm 2.2$ & 1966 & $2.4 \times 10^{-3}$ \\
2 & $0.025 \pm 0.005$ & $96 \pm 8$ & 11 & $20.0 \pm 2.2$ & 2578 & $8.6 \times 10^{-3}$ \\
3 & $0.025 \pm 0.005$ & $56 \pm 13$ & $85 \pm 1$ & $22.2 \pm 2.2$ & 3778 & $1.5 \times 10^{-3}$ \\
4 & $0.025 \pm 0.005$ & $100 \pm 6$ & 83 & $22.2 \pm 2.2$ & 2446 & $1.6 \times 10^{-3}$ \\
5 & $0.125 \pm 0.01$ & $49 \pm 5$ & $13 \pm 2$ & $22.2 \pm 2.2$ & 1923 & $2.0 \times 10^{-3}$ \\
6 & $0.125 \pm 0.01$ & $88 \pm 20$ & $15 \pm 1$ & $22.2 \pm 2.2$ & 2025 & $4.9 \times 10^{-3}$ \\
7 & $0.125 \pm 0.01$ & $50 \pm 3$ & 87 & $22.2 \pm 2.2$ & 4598 & $2.6 \times 10^{-3}$ \\
8 & $0.125 \pm 0.01$ & $102 \pm 9$ & 88 & $22.2 \pm 2.2$ & 2831 & $2.5 \times 10^{-3}$ \\
9 & $0.25 \pm 0.02$ & $49 \pm 2$ & $17 \pm 1$ & $21.7 \pm 0.8$ & 1039 & $6.5 \times 10^{-4}$ \\
10 & $0.25 \pm 0.02$ & $92 \pm 4$ & $16 \pm 1$ & $21.7 \pm 0.8$ & 3282 & $1.9 \times 10^{-3}$ \\
11 & $0.25 \pm 0.02$ & $51 \pm 2$ & $94 \pm 3$ & $22.2 \pm 2.9$ & 1530 & $9.6 \times 10^{-4}$ \\
12 & $0.25 \pm 0.02$ & $101 \pm 18$ & $90 \pm 3$ & $22.2 \pm 2.9$ & 1554 & $3.0 \times 10^{-3}$ \\
13 & $0.475 \pm 0.02$ & $52 \pm 3$ & 17 & $21.7 \pm 0.8$ & 1050 & $1.4 \times 10^{-3}$ \\
14 & $0.475 \pm 0.02$ & $98 \pm 11$ & $20 \pm 3$ & $21.7 \pm 0.8$ & 1232 & $2.9 \times 10^{-3}$ \\
15 & $0.475 \pm 0.02$ & $48 \pm 10$ & $87 \pm 2$ & $20.9 \pm 0.9$ & 1473 & $1.9 \times 10^{-3}$ \\
16 & $0.475 \pm 0.02$ & $99 \pm 16$ & $88 \pm 1$ & $20.9 \pm 0.9$ & 1049 & $4.9 \times 10^{-3}$ \\
\hline
\end{tabular}
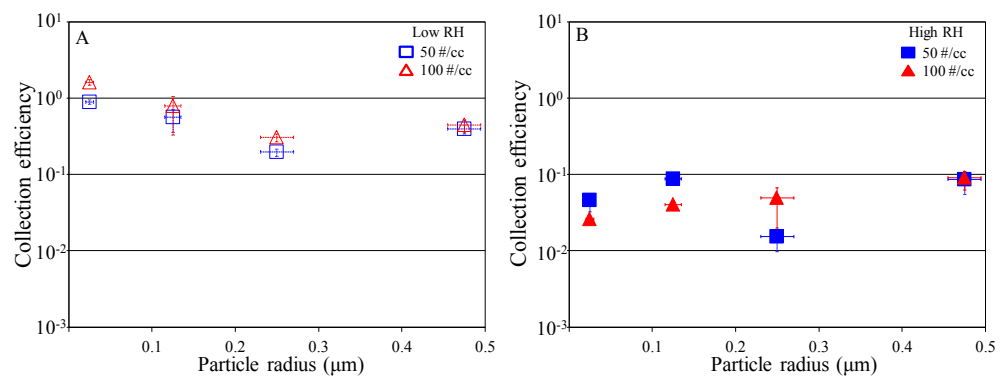

Figure 5. CE calculated as a function of particle radius. Shapes represent different aerosol concentrations. CE error bars are based on droplet size, aerosol size and aerosol number concentration measured from each experiment as described in Eq. (3). (a) Low-RH experiments. (b) High-RH experiments.

1 order of magnitude, when compared to otherwise similar high-RH experiments.

In previous experimental studies of collection, many considered significantly larger droplets (of drizzle or rain size; Leong et al., 1982; Pranesha and Kamra, 1993; Chate and Kamra, 1997) and particle sizes (super-micrometer; Owe Berg et al., 1970; Hampl and Kerker, 1972). For these reasons, we do not believe a direct comparison to our data is valid. This lack of comparison holds for other studies using aerosol in a similar size range but with much larger droplets (Hampl et al., 1971; Deshler, 1985; Vohl et al., 2001). The droplets used in the current work were significantly smaller, $>15$ times, than those used in the aforementioned experiments. Those studies reported lower CE values than measured here, in some cases by an order of magnitude. It has been shown in previous experimental and theoretical studies that the CE decreases with increasing droplet size (Daven- port and Peters, 1978; Wang et al., 1978; Leong et al., 1982; Pranesha and Kamra, 1993). It is likely that some of the differences in CE are also a result of different experimental conditions, such as droplets and/or particle charge.

Two experimental studies, Wang and Pruppacher (1977) and Lai et al. (1978), are roughly similar to our study, and both exhibit CE values slightly lower than the values from our measurements. A comparison is provided in Fig. 6. The differences in $\mathrm{CE}$ values could be a result of the different experimental conditions. For example, Wang and Pruppacher (1977) and Lai et al. (1978) used somewhat larger droplets (of 170-340 and 620 $\mu \mathrm{m}$, respectively), with higher charges than those used in the current work, $5 \times 10^{5}-7.1 \times 10^{6}$ elementary charges in Wang and Pruppacher (1977) and $6.6 \times 10^{8}-1.9 \times 10^{9}$ elementary charges in Lai et al. (1978). The larger droplets and higher droplet charges used by Wang and Pruppacher (1977) and by Lai et 

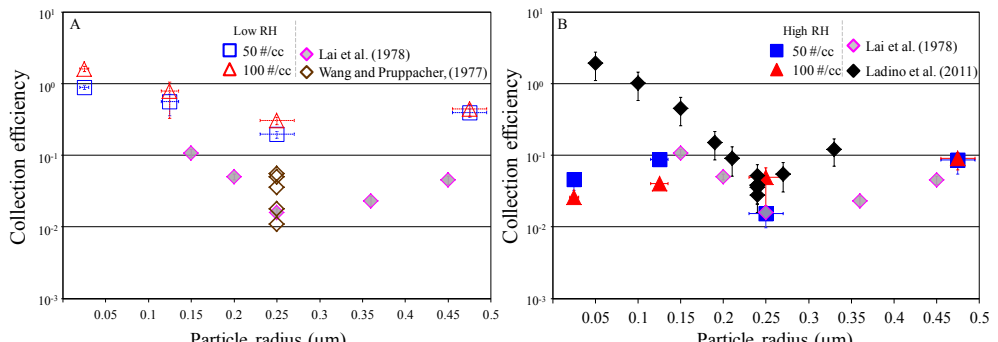

Figure 6. Comparison of CE from this study to previous experimental work. (a) Low-RH experiments. (b) High-RH experiments. Shapes (squares and triangles) represent different aerosol concentrations. Diamond shapes represent previous experimental work. Black diamonds are from Ladino et al. (2011), with RH $88 \pm 2 \%$, aerosol concentration $2000 \mathrm{~cm}^{-3}$ and droplet size of $12.8-20.0 \mu \mathrm{m}$. Brown diamonds are from Wang and Pruppacher (1977), with RH of $23 \pm 2 \%$, aerosol concentration of about $10^{17} \mathrm{~cm}^{-3}$ and droplet size of $170-340 \mu \mathrm{m}$. Pink diamonds are from Lai et al. (1978), with $620 \mu \mathrm{m}$ droplets and no information regarding the RH or aerosol concentration.

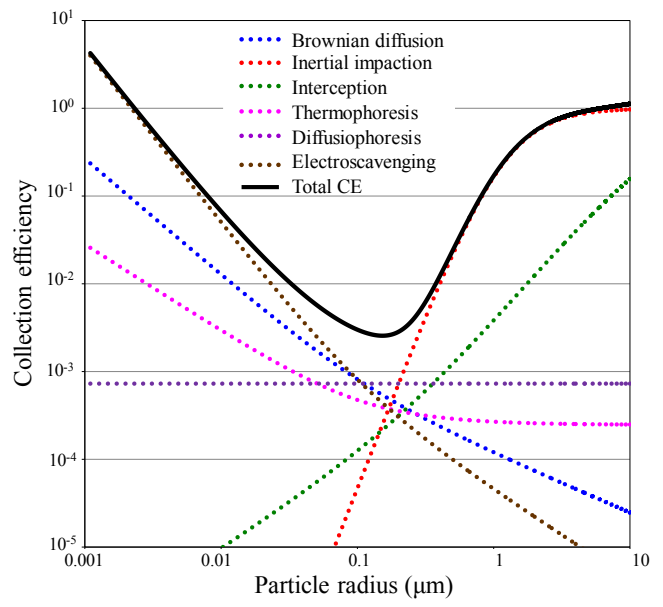

Figure 7. Theoretical $\mathrm{CE}$ and the individual contribution of each force. Calculation details are provided in the text. Experimental conditions of 400 elementary charges per droplet and one elementary charge per particle are used for a variable aerosol size, a droplet radius of $21.6 \mu \mathrm{m}$, an $\mathrm{RH}$ of $50 \%$ and room temperature.

al. (1978) could explain the differences between these works and ours, as will be discussed further in subsequent sections. Lai et al. (1978) did not mention the aerosol concentrations or RH conditions used in their work. Wang and Pruppacher (1977) used an RH condition similar to the low RH used in this study but with higher aerosol concentrations. It is expected that a higher aerosol concentration will increase the chance of collision between particles and droplets, which will increase the value of the ECR, but will not affect $\mathrm{CE}$, which is normalized.

The most similar experimental conditions to ours are those of Ladino et al. (2011). Ladino et al. (2011) used similar droplet (radius of 12.8-20 $\mu \mathrm{m}$ ) and particle sizes (radius of $0.05-0.33 \mu \mathrm{m})$. Experiments were conducted under RH conditions similar to our high-RH experiments $(88 \pm 2 \%)$. Although most of the experimental conditions were similar, there are noteworthy differences between the $\mathrm{CE}$ values of

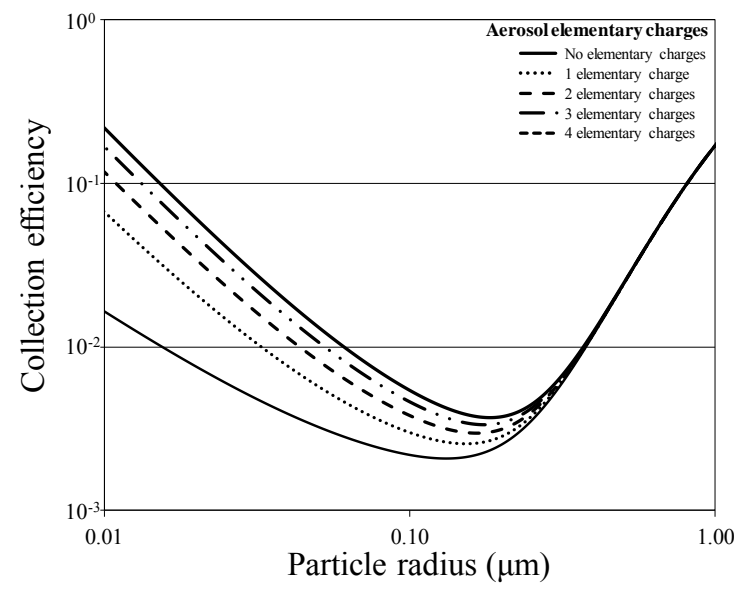

Figure 8. CE values for $50 \%$ RH and 400 elementary charges per droplets with different particles elementary charge for a droplet radius of $21.6 \mu \mathrm{m}$ and room temperature.

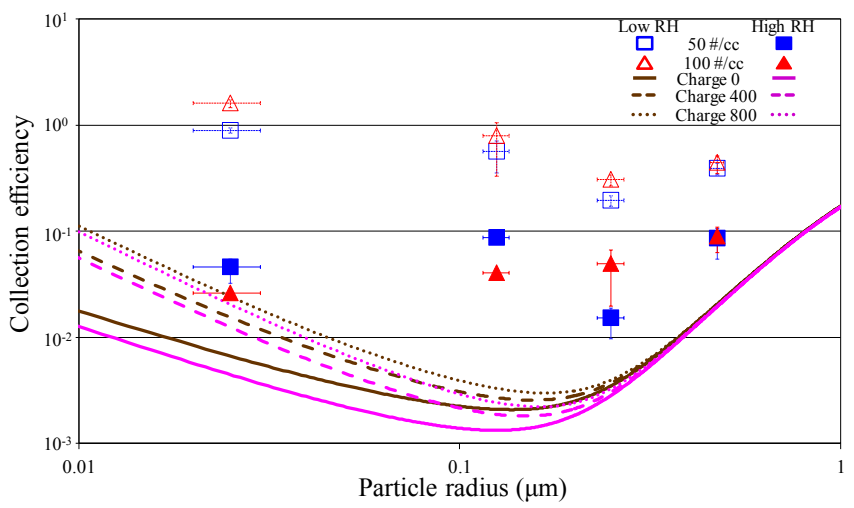

Figure 9. Comparison of CE experimentally determined in this study (points) with theoretical calculations (lines) where the charge number is elementary charge units per droplet (i.e., the lines span the range of measured droplet charge) and particles are singly charged. 

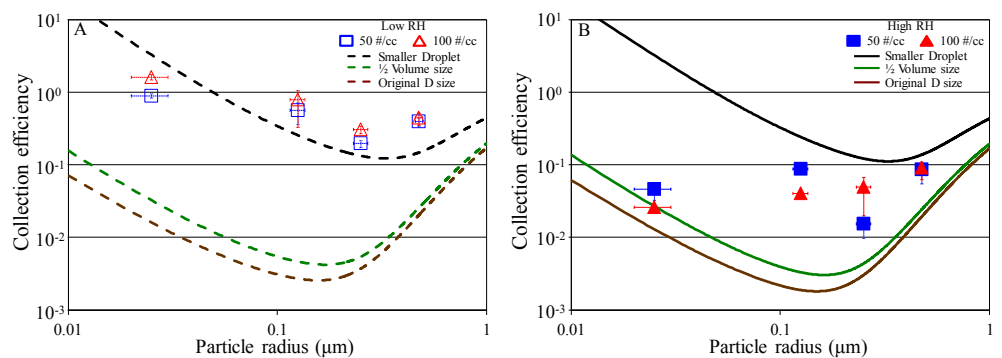

Figure 10. CE as a function of particle radius at low and high RH (a and $\mathbf{b}$, respectively). CE experimentally determined in this study (points) with theoretical calculations (lines). The lines represent calculation with different droplet sizes: the measured droplet size (brown), droplets with half the volume (green) and $5 \mu \mathrm{m}$ droplets (black). See text for details.

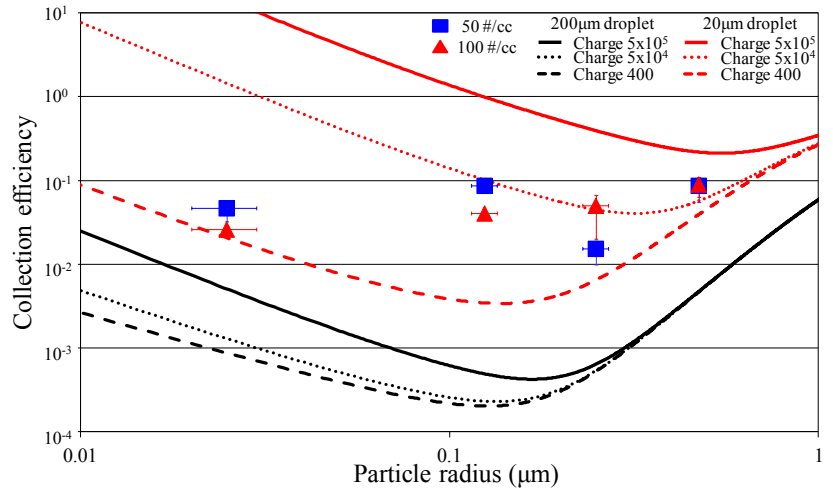

Figure 11. CE as a function of particle radius under high-RH conditions. CE experimentally determined in this study (points) with theoretical calculations (lines), where the charge number is in elementary charge units per droplet. Black lines are for CE of $200 \mu \mathrm{m}$ droplet size and red for $20 \mu \mathrm{m}$ droplet size.

Ladino et al. and those measured in this study, which are lower overall (Fig. 6). The main difference between the two studies is the droplet charge, which has a stronger impact on the electro-scavenging force. Ladino et al. (2011) used droplets with high charges, $5 \times 10^{4}$ elementary charges per droplet (Claudia Marcolli, personal communication, 2014), which are 2 orders of magnitude higher than the one used in this study. The higher droplet charge explains the higher CE values compared to those determined in this study.

In order to compare our experimental work with theoretical studies, a set of calculations combining six different forces, as described in Sect. 2.3, was conducted. Examples of theoretical forces and CE are given in Fig. 7. The properties used in these calculations included an air temperature of $22.5^{\circ} \mathrm{C}$, a pressure of $981 \mathrm{mbar}$, RH of $50 \%$, PSL particles with a density of $1000 \mathrm{~kg} \mathrm{~m}^{-3}$ of different sizes matching the experiments, a thermal conductivity of $0.1 \mathrm{~kg} \mathrm{~m} \mathrm{~s}^{-3} \mathrm{~K}^{-1}$ (Romay et al., 1998), and a constant droplet radius of $21.6 \mu \mathrm{m}$. Droplets were assumed to have 400 elementary charges, the average value determined by the electrometer experiments (see Sect. 2.1). These calculations were made for charged particles that contained one elementary charge per particle. Most particles in a Boltzmann distribution contain no charges and will therefore not be affected by electro-scavenging forces. The most common charge state other than neutral is a single charge, about $10 \%$ of particles, and this forms the basis of our calculation (Hinds, 1999). This is further supported by a decreasing effect of multiple charges when considering the effect on CE (Fig. 8).

As can be seen in Fig. 7, the total CE varies for different particle sizes. The contribution of Brownian diffusion decreases rapidly as particle size increases, while the contribution of inertial impaction increases rapidly as particle size increases. Interception forces also increase as particle size increases, but the effect is smaller than that of inertial impaction. The contribution of diffusiophoresis is smaller than that of thermophoresis for particles below $0.05 \mu \mathrm{m}$. The Greenfield gap is evident in this figure as the local minimum between the diffusion- and impaction-dominated regimes. This corresponds to a minimum at a particle size of $0.15 \mu \mathrm{m}$. In Fig. 7, electro-scavenging have a significant impact on the curves. Previous work by Wang et al. (1978), Byrne and Jennings (1993) and Tinsley et al. (2000) shows the presence of charge on droplets and aerosol can increase the CE throughout the Greenfield gap. Moreover, as described by Tinsley et al. (2001), the electrical effect is more important for smaller particle sizes $(<0.1 \mu \mathrm{m})$ than Brownian diffusion. This could explain why the Greenfield gap is highly pronounced in the data in Fig. 6, while it is more pronounced in the data of Lai et al. (1978) and Ladino et al. (2011).

In order to directly compare theoretical and measured CE, two cases were calculated: (1) droplet radius $21.4 \mu \mathrm{m}$ and low RH and (2) $21.9 \mu \mathrm{m}$ and high RH. In both calculations the range of values determined in the electrometer experiments, i.e., 0, 400 and 800 elementary charges per droplet, was used. The result of this comparison is shown in Fig. 9, where the points represent the experimental work and the lines represent the theoretical CE. Overall, the experimental work presents higher $\mathrm{CE}$ values compared to the theoretical CE. Differences between theoretical and measured CE may be considered a result of conditions not modeled theoretically 
or difficult to constrain experimentally. Possibilities include rare multiply charged particles, aerosol droplet electric interactions that are not fully considered (such as the induced dipole force), the evaporation rate of the droplets, variable terminal settling velocity due to changes in droplet size, and the presence of solute in the droplets.

As noted earlier, the droplets evaporated completely while in the chamber in both RH conditions. Since droplet size could not be determined precisely at the moment when collection occurred in the chamber, calculations of theoretical $\mathrm{CE}$ were performed for three relevant droplet sizes. The first was the original droplet size as measured from the droplet generator (21.4 and $21.9 \mu \mathrm{m}$, for low- and high-RH conditions, respectively) for the full droplet lifetime. The second was the droplet size with half the volume of the original droplet (radius of 17 and $17.4 \mu \mathrm{m}$, for low- and high-RH conditions, respectively) over the full lifetime. For the third, an extreme case was considered: droplets with a radius of $5 \mu \mathrm{m}$ for the full droplet lifetime. The results of these calculations are presented in Fig. 10. Overall, as droplet size decreases, $\mathrm{CE}$ values increase. In the extreme $5 \mu \mathrm{m}$ case, $\mathrm{CE}$ values increases by more than an order of magnitude. For the low-RH case the best agreement is with the $5 \mu \mathrm{m}$ case, which logically follows from the rapid evaporation of these droplets. In the high-RH case the experimental CE values fall nearest the half-volume case, which again logically follows since these droplets more slowly evaporate.

It is known that droplets carrying higher electric charge have higher CE (Barlow and Latham, 1983; Byrne and Jennings, 1993; Pranesha and Kamra, 1997a, b; Tinsley and Leddon, 2013; Tinsley et al., 2000; Tinsley, 2010), and this is consistent with our data in Fig. 9. Droplet size also affects CE, where smaller droplets have higher CE values (Lai et al., 1978; Pranesha and Kamra, 1996). Figure 11 shows a calculation of CE based on different droplet charges and sizes. Two droplet sizes were used: $20 \mu \mathrm{m}$, which is similar to the size used in this study and by Ladino et al. (2011), and $200 \mu \mathrm{m}$, which is the size used by Wang and Pruppacher (1977). Three different droplet charges were considered: 400 elementary charges, as used in this study; $5 \times 10^{4}$ elementary charges, as used by Ladino et al. (2011); and $5 \times 10^{5}$ elementary charges, the lower limit of charges used by Wang and Pruppacher (1977). As shown in Fig. 11, CE values increase as droplet charge increases. Droplet size and charge conditions can counteract each other in the case of larger droplets (lower CE) with higher charge (higher CE). We suggest this may explain the agreement found between the CE values measured in this study and those of Wang and Pruppacher (1977) and the disagreement between our values and those of Ladino et al. (2011). It should be noted that the experimental CE values fall within the region of the $20 \mu \mathrm{m}$ case. The $\mathrm{CE}$ values of the small particles $(<0.1 \mu \mathrm{m})$ match the theoretical CE, while for larger particles $(>0.1 \mu \mathrm{m})$ they are slightly higher. These differences could be a result of some conditions not modeled theoretically or conditions difficult to constrain experimentally, as discussed above.

\section{Conclusions}

An experimental setup has been constructed to measure the $\mathrm{CE}$ of $21.6 \mu \mathrm{m}$ radius water droplets with sub-micrometer PSL particles of $0.025,0.125,0.25$ and $0.475 \mu \mathrm{m}$ radius and concentrations of 50 and $100 \mathrm{~cm}^{-3}$. Two RH conditions, $15 \pm 3$ and $88 \pm 3 \%$, were used. Coagulated droplets were identified on a single-droplet basis using a single-particle mass spectrometer. CE values ranged from $2.0 \times 10^{-1}$ to 1.6 for the low-RH case and from $1.5 \times 10^{-2}$ to $9.0 \times 10^{-2}$ for the high-RH case.

The CEs measured here were found to be in agreement with previous experimental studies on droplets and aerosol particles of roughly similar sizes. Differences in measurements appear to be a result of variable (and sometimes undefined) aerosol and droplet charge, which has been theoretically shown to play an important role in CE. This finding highlights the need for explicit determination of droplet and aerosol charges when presenting results of collection experiments.

This technique overcomes some of the limitations inherent in previous studies which required a bulk collection of material. The analytical methods employed were limited by issues such as signal to noise and an inability to observe multiple collection events on single droplets. Moreover, very few experimental works have been performed with atmospherically relevant particles sizes (Radke et al., 1980; Andronache et al., 2006), another advantage of this technique. The droplet size and charge state used here are also consistent with atmospheric conditions.

Acknowledgements. We acknowledge the NOAA OAR Climate Program for supporting this project via grant number NA11OAR4310159. We thank Thomas Leisner, Luis Ladino and Sarvesh Garimella for their advice, assistance and guidance. We acknowledge Paul Ziemann and Karl Froyd and Charles Brock for the use of the electrometer and equipment to determine droplet charge. We also thank Claudia Marcolli and Baban Nagare for information about droplet charge in their experiment. We want to thank the reviewers for constructive comments which greatly helped in improving the paper.

Edited by: L. Zhang

\section{References}

Andronache, C., Grönholm, T., Laakso, L., Phillips, V., and Venäläinen, A.: Scavenging of ultrafine particles by rainfall at a boreal site: observations and model estimations, Atmos. Chem. Phys., 6, 4739-4754, doi:10.5194/acp-6-4739-2006, 2006. 
Barlow, A. and Latham, K. J.: A laboratory study of the scavenging of sub-micron aerosol by charged raindrops, Q. J. Roy. Meteorol. Soc., 109, 763-770, 1983.

Beard, K.: Experimental and numerical collision efficiencies for sub-micrometer particles scavenged by small raindrops, J. Atmos. Sci., 31, 1595-1603, 1974.

Beard, K. V., Ochs H. T., and Twohy, C. H.: Aircraft measurements of high average charges on cloud drops in layer clouds, Geophys. Res. Lett., 31, L14111, doi:10.1029/2004GL020465, 2004.

Byrne, M. and Jennings, S.: Scavenging of sub-micrometre aerosol particles by water drops, Atmos. Environ., 27, 2099-2105, 1993.

Chate, D.: Study of scavenging of sub-micrometer-sized aerosol particles by thunderstorm rain events, Atmos. Environ., 39, 6608-6619, 2005.

Chate, D. and Kamra, A.: Collection efficiencies of large water drops collecting aerosol particles of various densities, Atmos. Environ., 31, 1631-1635, 1997.

Croft, B., Lohmann, U., Martin, R. V., Stier, P., Wurzler, S., Feichter, J., Posselt, R., and Ferrachat, S.: Aerosol size-dependent below-cloud scavenging by rain and snow in the ECHAM5HAM, Atmos. Chem. Phys., 9, 4653-4675, doi:10.5194/acp-94653-2009, 2009.

Cziczo, D. J., Thomson, D. S., Thompson, T., DeMott, P. J., and Murphy, D. M.: Aerosol Mass Spectrometry Studies of Ice Nuclei and Other Low Number Density Particles, Int. J. Mass Spectrom., 258, 21-31, 2006.

Davenport, H. M. and Peters, L. K.: Field studies of atmospheric particulate concentration changes during precipitation, Atmos. Environ., 12, 997-1008, 1978.

Deshler, T.: Measurements of the rate at which sub-micrometer aerosol particles are scavenged by water drops, J. Aerosol Sci., 16, 399-406, 1985.

Feng, J.: A 3-mode parameterization of below-cloud scavenging of aerosols for use in atmospheric dispersion models, Atmos. Environ., 41, 6808-6822, 2007.

Greenfield, S.: Rain scavenging of radioactive particulate matter from the atmosphere, J. Atmos. Sci., 14, 115-125, 1957.

Grover S. N. and Pruppacher, H. R.: The Effect of Vertical Turbulent Fluctuations in the Atmosphere on the Collection of Aerosol Particles by Cloud Drops, J. Atmos. Sci., 42, 2305-2318, 1985.

Grover, S. N., Pruppacher, H., and Hamielec, A.: A numerical determination of the efficiency with which spherical aerosol particles collide with spherical water drops due to inertial impaction and phoretic and electrical forces, J. Atmos. Sci., 34, 1655-1663, 1977.

Hampl, V. and Kerker, M.: Scavenging of aerosol by a falling water droplet. Effect of particle size, J. Colloid. Interf. Sci., 40, 305308, 1972.

Hampl, V., Kerker, M., Cooke, D. D., and Matijevic, E.: Scavenging of Aerosol Particles by a Falling Water Droplet, J. Atmos. Sci., 28, 1211-1221, 1971.

Hinds, W. C.: Aerosol Technology: Properties, Behavior, and Measurement of Airborne Particles, Wiley, New York, 1999.

IPCC: Climate Change 2007: The Physical Science Basis, Contribution of Working Group I to the Fourth Assessment Report of the Intergovernmental Panel on Climate Change, Cambridge University Press, Cambridge, UK and New York, NY, USA, 2007.
Jung, C. and Lee, K.: Filtration of fine particles by multiple liquid droplet and gas bubble systems, Aerosol. Sci. Tech., 29, 389401, 1998.

Kerker, M. and Hampl, V.: Scavenging of aerosol particles by a falling water drop and calculation of washout coefficients, J. Atmos. Sci., 31, 1368-1376, 1974.

Ladino, L.: Experimental study on collection efficiency and contact freezing of aerosols in a new collision chamber, ETH Zurich, PhD Thesis, 2011.

Ladino, L., Stetzer, O., Hattendorf, B., Günther, D., Croft, B., and Lohmann, U.: Experimental study of collection efficiencies between sub-micrometer aerosols and cloud droplets, J. Atmos. Sci., 68, 1853-1864, doi:10.1175/JAS-D-11-012.1, 2011.

Lai, K., Dayan, N., and Kerker, M.: Scavenging of aerosol particles by a falling water drop, J. Atmos. Sci., 35, 674-682, 1978.

Leong, K., Beard, K., and Ochs III, H.: Laboratory measurements of particle capture by evaporating cloud drops, J. Atmos. Sci., 39, 1130-1140, 1982.

Liu, B. Y. H. and Pui, D. Y. H.: A sub-micrometer aerosol standard and the primary, absolute calibration of the condensation nuclei counter, J. Colloid. Interf. Sci., 47, 155-171, 1974.

Marshall, T. C. and Winn, W. P.: Measurements of charged precipitation in a New Mexico thunderstorm: Lower positive charge centers, J. Geophys. Res., 87, 7141-7157, 1982.

Murphy, D. M. and Thomson, D. S.: Laser ionization mass spectroscopy of single aerosol particles, Aerosol. Sci. Tech., 22, 237249, 1995.

Owe Berg, T. G., Gaukler, T. A., and Vaughan, U.: Collisions in Washout, J. Atmos. Sci., 27, 435-442, 1970.

Park, S., Jung, C., Jung, K., Lee, B., and Lee, K.: Wet scrubbing of polydisperse aerosols by freely falling droplets, J. Aerosol Sci., 36, 1444-1458, 2005.

Phillips, B. B. and Kinzer G. D.: Measurement of the size and electrification of droplets in cumuliform clouds, J. Meteorol., 15, 369-374, 1958.

Pranesha, T. S. and Kamra, A. K.: Experimental measurements of collection efficient of micron sized aerosol particles by Targo water drops, J. Aerosol Sci., 24, S415-S416, 1993.

Pranesha, T. S. and Kamra, A. K.: Scavenging of aerosol particles by large water drops. 1. Neutral case, J. Geophys. Res., 101, 23373-23380, 1996.

Pranesha, T. S. and Kamra, A. K.: Scavenging of aerosol particles by large water drops, 2, The effect of electrical forces, J. Geophys. Res., 102 23937-23946, 1997a.

Pranesha, T. S. and Kamra, A. K.: Scavenging of aerosol particles by large water drops 3. Washout coefficients, half-lives, and rainfall depths, J. Geophys. Res., 102, 23947-23953, 1997 b.

Prodi, F., Santachiara, G., Belosi, F., Vedernikov, A., and Balapanov, D.: Phoretic forces on aerosol particles surrounding an evaporating droplet in microgravity conditions, Atmos. Res., 142, 40-44, 2014.

Pruppacher, H. R. and Klett, J. D.: Microphysics of Clouds and Precipitation, Kluwer, Norwell, 1997.

Radke, L. F., Hobbs, P. V., and Eltgroth, M. W.: Scavenging of Aerosol Particles by Precipitation, J. Appl. Meteorol., 19, 715722, 1980.

Rasch, P. J., Feichter, J., Law, K., Mahowald, N., Penner, J., Benkovitz, C., Genthon, C., Giannakopoulos, C., Kasibhatla, P., Koch, D., Levy, H., Maki, T., Prather, M., Roberts, D. L., 
Roelofs, G.-J., Stevenson, D., Stockweli, Z., Taguchi, S., Kritz, M., Chipperfield, M., Baldocchi, D., McMurry, P., Barrie, L., Balkanski, Y., Chatfield, R., Kjellstrom, E., Lawrence, M., Lee, H. N., Lelieveld, J., Noone, K. J., Seinfeld, J., Stenchikov, G., Schwartz, S., Walcek, C., and Williamson, D.: A comparison of scavenging and deposition processes in global models: results from the WCRP Cambridge Workshop of 1995, Tellus B, 52, 1025-1056, 2000.

Romay, F. J., Takagaki, S. S., Pui, D. Y. H., and Liu, B. Y. H.: Thermophoretic deposition of aerosol particles in turbulent pipe flow, J. Aerosol Sci., 29, 943-959, 1998.

Santachiara, G., Prodi, F., and Belosi, F.: A review of thermo- and diffusiophoresis in the atmospheric aerosol scavenging process. Part 1. Drop scavenging, Atmos. Clim. Sci., 2, 148-158, 2012.

Slinn, W. and Shen, S.: Anisotropic Brownian diffusion and precipitation scavenging of sub-micrometer particles, J. Geophys. Res., 75, 2267-2270, 1970.

Starr, J. and Mason, B.: The capture of airborne particles by water drops and simulated snow crystals, Q. J. Roy. Meteorol. Soc., 92, 490-499, 1966.

Thomson, B. A. and Iribarne, J. V.: The fate of electrical charges in evaporating cloud droplets, Rev. Geophys. Space Phys., 16, 431-434, 1978.

Tinsley, B. A.: Electric charge modulation of aerosol scavenging in clouds: Rate coefficients with Monte Carlo simulation of diffusion, J. Geophys. Res., 115, D23211, doi:10.1029/2010JD014580, 2010.

Tinsley B. A. and Leddon, D. B.: Charge modulation of scavenging in clouds: Extension of Monte Carlo simulations and initial parameterization, J. Geophys. Res., 118, 8612-8624, doi:10.1002/jgrd.50618, 2013.
Tinsley, B. A., Rohrbaugh, R. P., Hei, M., and Beard, K. V.: Effects of image charges on the scavenging of aerosol particles by cloud droplets, and on droplet charging and possible ice nucleation processes, J. Atmos. Sci., 57, 2118-2134, 2000.

Tinsley, B. A., Rohrbaugh, R., and Hei, M.: Electroscavenging in clouds with broad droplet size distributions and weak electrification, Atmos. Res., 59, 115-135, 2001.

Tinsley, B. A., Zhou, L., and Plemmons, A.: Changes in scavenging of particles by droplets due to weak electrification in clouds, Atmos. Res., 79, 266-295, 2006

Vali, G.: Ice nucleation - A review, in: Nucleation and Atmospheric Aerosols, edited by: Kulmala M. and Wagner, P. E., Elsevier, 271-279, 1996.

Vohl, O., Mitra, S., Diehl, K., Huber, G., Wurzler, S., Kratz, K., and Pruppacher, H.: A wind tunnel study of turbulence effects on the scavenging of aerosol particles by water drops, J. Atmos. Sci. 58, 3064-3072, 2001.

Wang, P. K. and Pruppacher, H.: An experimental determination of the efficiency with which aerosol particles are collected by water drops in subsaturated air, J. Atmos. Sci., 34, 1664-1669, 1977.

Wang, P. K., Grover, S. N., and Pruppacher, H. R.: On the effect of electric charges on the scavenging of aerosol particles by clouds and small raindrops, J. Atmos. Sci., 35, 1735-1743, 1978.

Wang, X., Zhang, L., and Moran, M. D.: Uncertainty assessment of current size-resolved parameterizations for below-cloud particle scavenging by rain, Atmos. Chem. Phys., 10, 5685-5705, doi:10.5194/acp-10-5685-2010, 2010.

Wiedensohler, A.: An approximation of the bipolar charge distribution for particles in the submicron size range, J. Aerosol Sci., 19, 387-389, 1988. 